\title{
Dysaesthesia in the mental nerve distribution triggered by a foreign body: a case report
}

\author{
Panagiotis Kafas*1, Tahwinder Upile ${ }^{2,3}$, Nikolaos Angouridakis ${ }^{4}$, \\ Christos Stavrianos ${ }^{5}$, Nikolaos Dabarakis ${ }^{1}$ and Waseem Jerjes ${ }^{2,3,6}$
} \begin{abstract}
Greece and ${ }^{6}$ Unit of Oral and Maxillofacial Surgery, UCL Eastman Dental Institute, UK
Email: Panagiotis Kafas* - pankafas@yahoo.com; Tahwinder Upile - mrtupile@yahoo.com; Nikolaos Angouridakis - nikos_angouridakis@yahoo.gr; Christos Stavrianos - stavrian@med.auth.gr; Nikolaos Dabarakis - nikosd@dent.auth.gr; Waseem Jerjes - waseem_wk1@yahoo.co.uk

* Corresponding author
\end{abstract}

Address: ${ }^{1}$ Department of Oral Surgery and Radiology, School of Dentistry, Aristotle University, Thessalonica, Greece, ${ }^{2} \mathrm{Head}$ and Neck Centre, University College London Hospital, UK, ${ }^{3}$ Department of Surgery, University College London Medical School, UK, ${ }^{4}$ Department of ENT, School of Medicine, Aristotle University, Thessalonica, Greece, ${ }^{5}$ Department of Endodontics, School of Dentistry, Aristotle University, Thessalonica,

Published: 28 October 2009

Cases Journal 2009, 2:169 doi:10.1186/1757-1626-2-169

This article is available from: http://www.casesjournal.com/content/2/1/169

(c) 2009 Kafas et al; licensee BioMed Central Ltd.

This is an Open Access article distributed under the terms of the Creative Commons Attribution License (http://creativecommons.org/licenses/by/2.0), which permits unrestricted use, distribution, and reproduction in any medium, provided the original work is properly cited.
Received: 19 October 2009

Accepted: 28 October 2009

\begin{abstract}
Introduction: Foreign bodies' entrapments in the mandibular and submandibular regions are quite common.

Case presentation: We report an unusual case of foreign body (amalgam filling) entrapment over the mental foramen causing dysaesthesia in the distribution of the mental nerve. An interesting sign was blue discoloration of the overlaying oral mucosa which was interpreted as amalgam tattooing.
\end{abstract}

Conclusion: Surgical removal of the foreign object eliminated the reported symptoms.

\section{Case presentation}

A 55-years-old Caucasian female was referred complaining of dull ache and numbness in the lower left mandibular region; the pain radiated towards the midline. No other associated symptoms were reported.

The patient had a remarkable medical history. Dental history included few dental extractions and restorations over the years with no reported complications. No allergies were reported. The patient alcohol consumption was below the recommended safe limit; while she smoked an average of 10 cigarettes/day for the last 20 years.

Intra-oral examination revealed a slight bluish mucosal discoloration distal to the lower left first premolar (Figure 1 ). The area was tender to palpation; also gentle pressure resulted in pain triggering and radiation to the midline along the body of mandible.

Initial investigations involved a unilateral dental panoramic tomography which revealed a 2-3 mm teardrop-like radiopague area or mass (foreign body) surrounded by or embedded in a radiolucent area (Figure 2). Careful assessment led to the conclusion that this represents an amalgam material that is located over the mental foramen, with surrounding chronic inflammation and bone remodeling. Hence, the pain was triggered by pressure and radiated along the distribution of the mental nerve.

Open surgical approach under local anaesthesia was employed with care, especially when exposing the mental nerve. Curettage, removal of the foreign body and debri- 


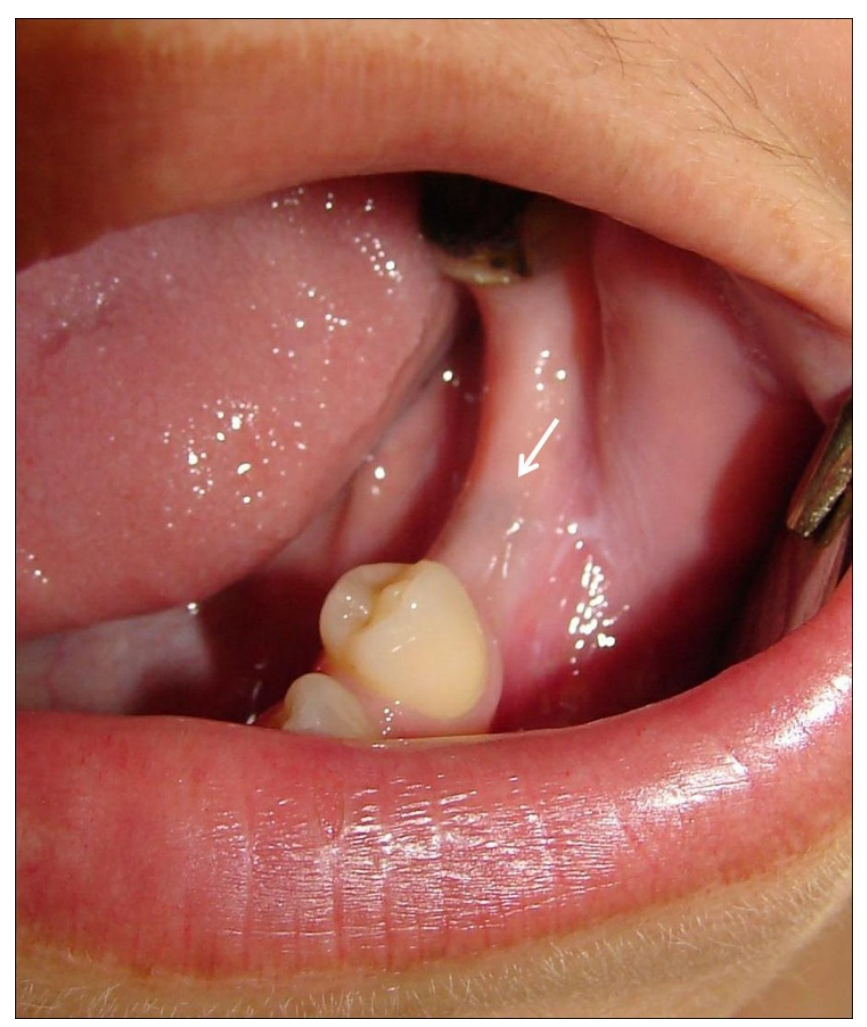

Figure I

Intra-oral image showing blue discolouration of the alveolar mucosa (arrow) caused by soft tissue infiltration of amalgam components.

dement (Figure 3) took place and the wound was sutured with $3 / 0$ polyglactin. The removed foreign body measured $2 \mathrm{~mm}$ in diameter. The patient was covered with NSAIDs and antimicrobials for 1 week. Follow-up at two weeks revealed symptoms resolution. At three months, the patient remained symptom-free.

\section{Discussion}

Foreign bodies' entrapments in the mandibular and submandibular regions are quite common. Inflammation and foreign body granuloma can occur following entrapment of amalgam filling, broken needle, air turbine bur, endodontic filling material, broken toothbrush and sometimes tooth displacement [1-7].

Foreign body (inflammatory) reaction or injury of inferior alveolar nerve (IAN)/mental nerve may be classified into metallic or non-metallic, temporary or permanent, chemico-mechanical or thermal [8]. According to "Steddon classification for peripheral nerve injury", there are three basic injuries: neurapraxia, axonotmesis and neurotmesis [9]. Neurapraxia is a temporary conduction block after mild compression of the nerve trunk (i.e. paraesthesia or dysaesthesia of the lip and chin region in case of

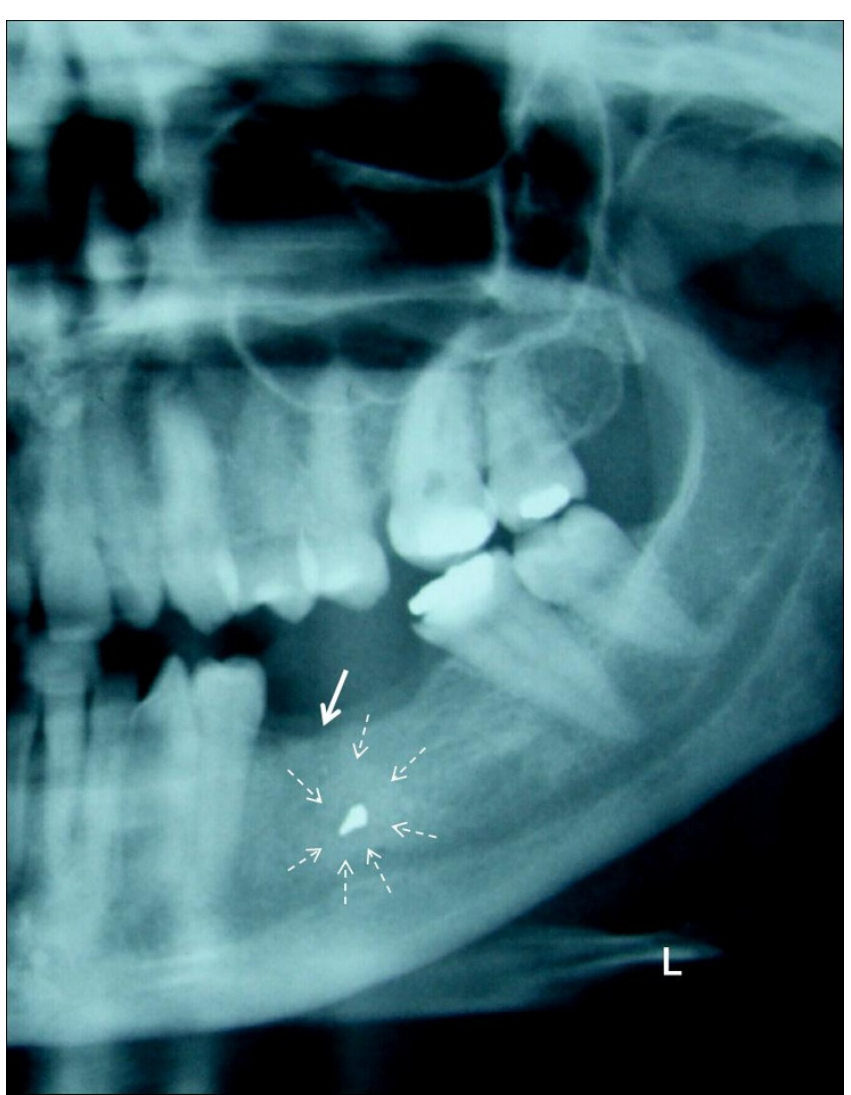

Figure 2

Unilateral panoramic tomography showing a teardrop-like radio-opaque foreign body in the mandible. Chronic inflammation and bone remodelling can be seen in the area over the mental nerve and around the foreign body (dashed arrows). Recent dental extraction in the area is apparent on the radiograph as well (non-dashed arrow).

IAN/mental nerve) [10]. Axonotmesis, a more serious condition, results from degeneration of the afferent fibers as a result of internal/external irritation (i.e. anaesthesia) [11]. While, in neurotmesis the nerve is completely severed which results in permanent paraesthesia, which can be corrected with microneurosurgical interventions with variable prognosis [9]. In our patient, dysaesthesia (neurapraxia) in the distribution of the mental nerve resulted from compression of the nerve with no structural damage; symptoms can be worsened with chronic irritation and perineural inflammation.

Paraesthesia or dysaesthesia in the distribution of the IAN/mental nerve can be linked to overfilling of root canals close to the nerve [8], severe endodontic infection involving the nerve [12], compression during dental/surgical instrumentation $[13,14]$, mandibular fracture distal to the lingula [15], foreign body reaction [16], pathology 


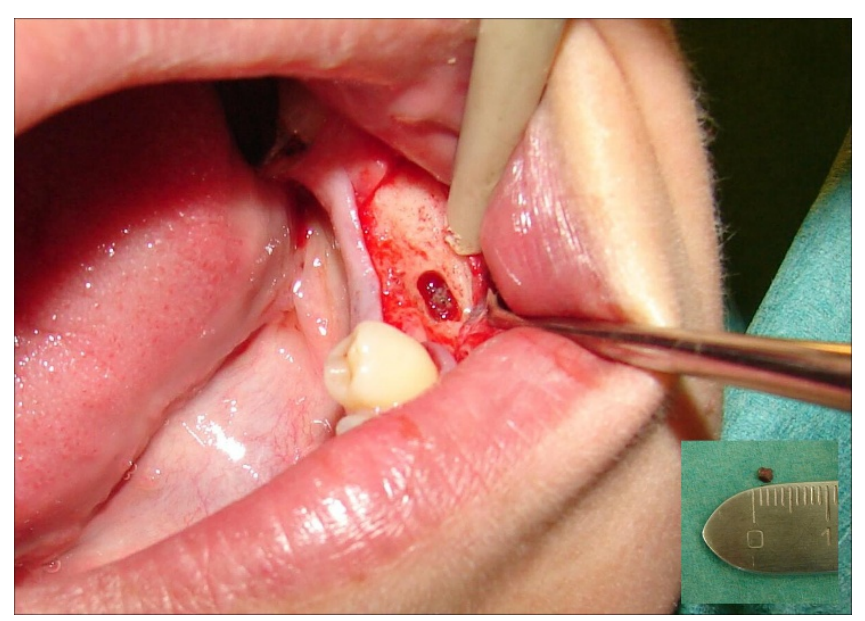

Figure 3

Removal of the foreign object performed through a minimal-size bony "window" under local anaesthesia. Inset: the extracted amalgam filling was $2 \mathrm{~mm}$ in size.

[17], orthognathic surgery $[18,19]$ and improper implant placement [15].

Patients presenting with sensory symptoms in the distribution of the IAN/mental nerve area should be assessed carefully. Detailed history, including recent interventions, should be taken; this should be followed by careful examination and radiological investigation. In our patient the presence of amalgam tattooing sign has lead to the conclusion that the problem could be related to amalgam filling. Amalgam tattooing of the oral mucosa results from metallic particles infiltration, which may results in blue discoloration. Investigations was with a unilateral OPG which confirmed the findings.

Surgical removal of the foreign body is the most accepted intervention. In our case, this has resulted in symptoms resolution in a short period of time. However care must be taken during the debridement of the area to avoid any further irritation/damage to the nerve.

In this interesting case, the most accepted justification is that a small amalgam filling (chip) was entrapped in the bony socket of the previously extracted second premolar and caused this local irritation. The host defence mechanism induced inflammatory reaction followed by granulation tissue formation; the chronic inflammation in the area has lead to bone remodeling around the foreign object. It is believed that the origin of the filling material might be from the extracted (restored) tooth or from the $2^{\text {nd }}$ molar which has a missing amalgam filling in its mesial side. The origin of the tattooing of the oral mucosa could be associated with the previously extracted (restored) tooth or occurred soon after entrapment of the amalgam material in the socket.

Clinicians' should be aware of the fact that foreign body's entrapment can lead to neurological complications following dental extractions; and this usually resolves with surgical removal of the insult material. Usually close monitoring is advised in such a case.

\section{Abbreviations}

IAN: Inferior Alveolar Nerve.

\section{Competing interests}

The authors declare that they have no competing interests.

\section{Authors' contributions}

PK, TU, NA, CS, ND, WJ were major contributors in assessing the case data, reviewing and writing the manuscript. All authors read and approved the final manuscript.

\section{Consent}

Written informed consent was obtained from the patient for publication of this case report and accompanying images. A copy of the written consent is available for review by the Editor-in-Chief of this journal.

\section{References}

I. Silveira VA, de Carmo ED, Colombo CE, Cavalcante AS, Carvalho YR: Intraosseous foreign-body granuloma in the mandible subsequent to a 20-year-old work-related accident. Med Oral Patol Oral Cir Bucal 2008, 13:E657-60.

2. Shah A, Mehta N, Von Arx DP: Fracture of a dental needle during administration of an inferior alveolar nerve block. Dent Update 2009, 36:20-2.

3. Yalcin S, Aktas I, Emes Y, Atalay B: Accidental displacement of a high-speed handpiece bur during mandibular third molar surgery: a case report. Oral Surg Oral Med Oral Pathol Oral Radiol Endod 2008, 105:e29-31.

4. Karasu HA, Uyanik LO, Koçyiğit ID: Displacement of avulsed tooth into soft tissue of chin resulting from epileptic attack trauma. N Y State Dent J 2005, 7 I:26-8.

5. Ahlgren FK, Johannessen AC, Hellem S: Displaced calcium hydroxide paste causing inferior alveolar nerve paraesthesia: report of a case. Oral Surg Oral Med Oral Pathol Oral Radiol Endod 2003, 96:734-7.

6. Oza N, Agrawal K, Panda KN: An unusual mode of injuryimplantation of a broken toothbrush medial to ramus: report of a case. ASDC J Dent Child 2002, 69:193-5.

7. Köseğlu BG, Gümrü O, Kocaelli HA: Lower third molar displaced in the sublingual space. Dentomaxillofac Radiol 2002, 31:393.

8. Gallas-Torreira MM, Reboiras-López MD, García-García A, GándaraRey J: Mandibular nerve paresthesia caused by endodontic treatment. Med Oral 2003, 8:299-303.

9. Seddon HI: Three types of nerve injury. Brain 1943, 66:237-288.

10. Donoff RB: Nerve regeneration: basic and applied aspects. Crit Rev Oral Biol Med 1995, 6: 18-24.

II. Becelli R, Renzi G, Carboni A, Cerulli G, Gasparini G: Inferior alveolar nerve impairment after mandibular sagittal split osteotomy: an analysis of spontaneous recovery patterns observed in 60 patients. J Craniofac Surg 2002, I3:315-320.

12. Morse DR: Infection-related mental and inferior alveolar nerve paresthesia: literature review and presentation of two cases. J Endod 1997, 23:457-460. 
13. Dolanmaz D, Yildirim G, Isik K, Kucuk K, Ozturk A: A preferable technique for protecting the inferior alveolar nerve: coronectomy. J Oral Maxillofac Surg 2009, 67: 1234-8.

14. Kafas P, Jerjes W, Hopper C, Dalabiras S: Complications following lower third molar surgery in a specific age group. Surg J 2007, 2:50-54.

15. Poort LJ, van Neck JW, Wal KG van der: Sensory testing of inferior alveolar nerve injuries: a review of methods used in prospective studies. J Oral Maxillofac Surg 2009, 67:292-300.

16. Mazinis E, Lambrianidis T, Margelos J: Detection of a residual foreign body during root canal treatment. J Endod 2005, $31: 691-3$.

17. Sumer M, Bas B, Yildiz L: Inferior alveolar nerve paresthesia caused by a dentigerous cyst associated with three teeth. Med Oral Patol Oral Cir Bucal 2007, I 2:E388-390.

18. Farronato G, Garagiola U, Farronato D, Bolzoni L, Parazzoli E: Temporary lip paresthesia during orthodontic molar distalization: report of a case. Am J Orthod Dentofacial Orthop 2008, I33:898-90|.

19. Seo K, Tanaka Y, Terumitsu M, Someya G: Characterization of different paresthesias following orthognathic surgery of the mandible. J Oral Maxillofac Surg 2005, 63:298-303.

Publish with Bio Med Central and every scientist can read your work free of charge

"BioMed Central will be the most significant development for disseminating the results of biomedical research in our lifetime. "

Sir Paul Nurse, Cancer Research UK

Your research papers will be:

- available free of charge to the entire biomedical community

- peer reviewed and published immediately upon acceptance

- cited in PubMed and archived on PubMed Central

- yours - you keep the copyright 